\title{
Augusto Iglesias
}

\section{El factor psiquico en la interpre- tación de la Historia y de la Leyenda}

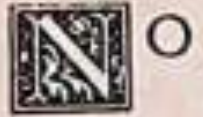

hay duda que durante largo tiempo existió lamentable confusión en el estudio y los mélodos que se dedicaron al conocimiento del pasado. En realidad, no hubo un conceplo claro de la Historia, y las vagas explicaciones que se dieron para prestigiar a esta rama del saber, no impidieron el descrédito ni la fría desconfianza de los doclos en que más tarde se viera envuelta.

Esta desconfianza y este descrédito eran justificados. Me referiré de paso a uno de los aspectos del problema que obligan a considerarlos asi: la falta de crílica. El trabajo histórico es, anfes que nada, actividad critica; y sólo en el primer cuarto del siglo XIX pudo ésta aplicarse, gracias a los avances de la Ciencia, con la honradez y la severidad profesional de que era menester en los mélodos de investigación.

Lógicamente, el fenómeno evolutivo que anoto-y que dió cima a una serie de ininterrumpidos esfuerzos que, sin marcar limite preciso, se venian sumando desde la época renacentista - luvo que delerminar en nuestro siglo un notable aclaramiento de lo que era en lo antiguo y de lo que es ahora en lo moderno el sentido histórico de la Historia.

Veamos.

Para el hombre antiguo, la Hisloria era lodo lo que venia del pretérilo, con la fianza-en la mayoria de los casos, sim- 
plemente cordial-de un prestigio de verdad. El pasado mostrábasc a corta distancia como un bloque de piedra macizo y duro. A poco de estirar la mano investigadora se tropezaba con el obstáculo insalvable. $Y$ cuando se creyó divisar algún desfiladero que ofreciese la posibilidad de una incursión a través de lo desconocido, a las primeras correrías no tardó en romperse el límile humano en los dominios de la milologia. Egipto, India, Grecia, Roma, podrian confirmar esle aserlo.

Es efeclivo que tan grandes inconvenientes tuvieron que disminuir, día a dia, a medida que la cultura humana iba en aumento. Pero, aun muy avanzada la critica, pocos hechos lograron sorprender en contra si ellos venian arrastrados en esa ola multiforme de los documentos y de la afirmación rotunda de la tradición. ¡Hubiérase dicho de la Historia de aquel entonces, que más que inquietud para sabios era disciplina para creyentes!

- ¿Hay consenso unánime? ¿es un desteñido papel el que lo dice?-preguntaban los erudilos de aquellas parroquias. Y si la conlestación fué afirmativa, no habia discusión posible. El hecho era insospechablemente verdadero.

$\mathrm{Y}$ no hay por qué alarmarse. Es más cómodo creer que disculir, admitir que criticar, acumular documentos que pesarlos. $\mathrm{Y}$ es también más agradable. El que hace examen crílico de los documenlos sacrifica alguno; lo cual fácilmente considera una pérdida, y no otra cosa. el que lo ha recogido.

Estos defeclos que el historiógrafo moderno trata de suprimir. son los que han permitido apreciar un mismo acontecimiento histórico, según el punto de vista que se eligiera, de modo distinto y muchas veces hasta de opuesta manera.

De acuerdo con las observaciones que indico. no me sorprende que haya personas que crean en la vida sobrenalural de Buda como en una cosa comprobada: asi como no me admira

- Introducción a los Esfudios Hisfóricos: C. V. Langlois y C. Seignobos. Daniel Jorro, Edifor,-Madrid, 1913. 
que, para honra del buen sentido, existan otras que sólo le dan al aspecto taumatúrgico el valor legendario que merece.

- Se desprende de lo dicho que aun subsiste, para infinidad de criterios, un problema de añejo sabor: el que. llevado a solución, demarcó de manera precisa las órbitas de la Historia y de la Leyenda.

Al estudiarse, como simples antecedentes, los escollos que este crilerio reaccionario ha opuesto al avance de la investigación histórica a base de métodos positivos, admira, en verdad. la resistencia psíquica con que grupos aislados, y muchas veces colectividades enteras, defienden la vida de los milos y de las supersticiones populares como si éslas fueran intangibles dogmas de le.

Resultará beneficioso traer a memoria algunos casos.

Todos reconocen, a lo menos en lérminos generaleș. la supremacia de los pueblos meridionales sobre cualesquiera olros, en cuanto ésta se refiera a una mayor exaltación de los sentimientos religiosos. Fenómeno psicológico poco esludiado o simple coincidencia geográfica, lo cierlo es que los paises mediterráneos dieron más nilidas vidas de perfección a la gloria ećlesiástica que todo el norle de Europa reunido. Tierra de santos fueron Italia y Francia, y lo fué, también, en el pretérito, la Peninsula hispana.

Pues bien, en tiempos de Urbano VIII. llegó a Roma, procedente de una de las iglesias españolas, un pedido de los fieles en que suplicaban humildemente al Pontifice bendición apostólica e indulgencia plenaria para los que acudieran a la fiesta de San Viar, protector admirable de aquellas comarcas, y de cuyo cuerpo se decian poseedores los piadosos parroquianos.

Indudablemente sorprendido por aquel nombre que no aparecia en el Santoral, y del cual no existian dalos en la Casa de Pedro, Urbano VIII ordenó estudiar el asunto. Graves epigrafistas y doctos arqueólogos, entre los mejores del clero español, se de- 
dicaron a la tarea admirándose, apenas ésta se inició, de que todas las pruebas sobre la existencia de San Viar se redujeran a una piedra colocada en el lugar en que se creia sepultado el santo y en la cual se leia una letra y una palabra: -S. Viars: caracteres que el tiempo habia lamido inmisericorde hasta hacerlos palidecer exlenuados en el curioso monumento.

¿Para qué más?

Algún critico en materias que no son de su amaño habria quedado satislecho, pero los sabios españoles, examinando hábilmente la vaga prueba en que se apoyaba la leyenda. descubrieron que se trataba de una antigua inscripción, en partes casi enteramente borrada, y en la cual mencionábase a un praefectu $S$. VIARum, o inlendente de los caminos públicos en tiempos de la dominación romana.

por supuesto que San Viar había realizado, hasta esa fecha, infinidad de milagros...

Ya en este terreno, saben los hombres cultos cómo es de históricamente falsa $-y$ de extendida, sin embargo. con prestigios de verdad-la leyenda esa que sostiene que Isabel la Católica hubo de vender sus joyas para comprar las naves que utilizara Colón en el viaje aventurero que dió por frulo el descubrimiento de América. Saben, también, los que estudian estas cosas, que aun personajes que aparecen como escribiendo libros. son, ellos mismos, de muy dudosa existencia: v. gr., Diógenes Laercio, el cautor, de Vidas. Opiniones y Sentencias de los Filósofos más Ilustres.

No agotaré, y no seria posible tampoco agotar en el espacio de un artículo de revista, los mil y mil ejemplos que podría traer a colación en esle sentido. Me bastará, para el objeto que persigo, un caso más que pone en claro cómo es de poderoso el factor psíquico en la interpretación de la Historia y de la Leyenda, y cómo es de improbo y rudo el trabajo para aquellas personas, que disciplinadas en el respeto a la verdad y a los métodos positivos de investigación. se encuentran de

- Smedt. Principes de Crifique Historique, Cap. XI, p. 192, Paris, 1883. 
pronto con hombres, o con todo un núcleo nacional, que por un lado aceptan la aulenticidad de los viajes de Ulises, y por el otro llaman ridiculez al método analógico o comparativo; método que. al estudiar una leyenda o un hecho histórico impreciso, busca los puntos de contacto que lenga con otras tradiciones o acontecimientos similares de cualquier pais o latilud. Bastaria preguntarles a estas personas: - ¿Acaso los símbolos, las leyendas o las interpretaciones miticas del universo no han dado vuelta al mundo?, Pero seria trabajo inútil: no hay fuerza capaz de convencer a un cerebro poco dúctil y por ende supersticioso.

A pesar de lo dicho, el caso a que me voy a referir puede ser útil a las personas libres de prejuicios y que se interesen por esta clase de esludios. Hablo de la leyenda de Guillermo Tell.

Surgia esle héroe, en la historia europea, como el liberfador de Suiza. Contaba la tradición que el 17 de Enero de 1307. reunidos en la pradera de Grutli, un grupo de patriotas juró independizar los cantones de la dominación austriaca. El golpe debia realizarse más larde, en la noche del $10^{\circ}$ de Enero. $\mathrm{Y}$ es en esa época, precisamente, en que, como decoración soberbia de las montañas, de pie sobre el risco, aparece Guillermo Tell...

Pero Hermann Guessler, el gobernador austriaco, no estaba tranquilo. Algo le decía a su espiritu que estaba cercano el levantamiento del pueblo al cual sojuzgaba. „Para probarlo escribe el historiador suizo Enrique Zschokke - -y para humillarlo, hizo colocar su sombrero en la punta de una vara, en cl pais de Uri, y ordenó que lodos los que pasaran se inclinasen respetuosamente delante de este simbolo de la autoridad ausIriaca. Proponiase reconocer por este medio a los enemigos de Austria.

-Guillermo Tell, de Burglen, hábil arquero, uno de los hombres de Grulli. pasó delante del sombrero, pero no se inclinó. Inme-

- Zschokke, Histoire de la nation suisse (trad. francesa de Monnard). Chap. XII, cit. por Barros Arana, Obras compl. T. 9, pág. 8. 
diatamente lo tomaron para conducirlo delante del gobernador. Esle lo apostrofó lleno de cólera. AArquero lemerario - le dijo.- - quiero que tu arte te sirva de suplicio. Pon una manzana sobre la cabeza de tu hijo menor: apúntale y guárdate bien de errar el tiro.s El niño fué amarrado: se puso una manzana sobre su cabeza, y se colocó al padre a una distancia considerable. Apunta, parte el dardo. la manzana queda atravesada: el pueblo lanza gritos de contento. Pero Guessler dice a Tell: - ¿¿Para qué llevas un segundo dardo?. Tell respondió: .Si el uno no hubiese dado en la manzana, el otro habria llegado a tu corazón.)

-El tirano ordenó que se cargase de cadenas a esle hombre valiente, y que se le amarrase en el fondo de una embarcación para conducirlo bajo su inmediala vigilancia a Kussnacht. No juzgó prudente encerrarlo en una cárcel del país de Uri, a causa de las disposiciones del pueblo; y por otra parte. los derechos de la nación se oponían a que se le enviase fuera del pais, a una cárcel austriaca. Temiendo el agrupamiento de la muchedumbre, el gobernador dió apresuradamente la orden de partida, a pesar de un viento contrario que soplaba con ímpetu. Tan pronto la embarcación parecía bajar a un abismo. como las olas espumosas la llenaban de agua. Los remeros desesperaban de salvarse. Mientras más se avanzaba, más aumentaba el peligro en medio de las inmensas rocas corladas en escarpe que forman las orillas del lago, y se elevan al cielo como murallas. En el colmo de la desesperación. Guessler hizo quilar las cadenas a Tell, a fin de que por su habilidad salvase la embar. cación. Este se dirigió hacia el costado desnudo del Axember. donde una roca en forma de meseta avanza sobre el lago. Alli se lanza a tierra, e impulsa de nuevo la embarcación con el pie. Tell queda al abrigo de todo peligro: Guessler, a merced de las olas.

-Escapado del peligro. trepa la montaña y se salva en el país de Schwytz. Triste y pensativo, se decia: e¿Dónde huir de la cólera del tirano? Si me escapo, mi mujer y mi hijo le servirán de rehenes. ¿Ante qué tribunal podré citar a Guessler? 
El rey mismo no escucha los gritos del pueblo. iPues bien! Ya que las leyes no tienen auloridad, ya que no hay justicia entre el opresor y el oprimido, nosotros dos. Guessler y yo. estamos fuera de la ley. Nuestra única ley es la necesidad de defenderse. $\mathrm{Si}$ es necesario que mi mujer, mi hijo y mi patria perezcan inocentes, o que tú mueras cargado de crimenes, muere, tirano, y que la libertad revival,

-Animado por estos pensamientos, y armado con un arco y una flecha, Tell vuelve hacia Kussnacht y se oculta en un camino extraviado. El gobernador pasa por alli cerca: la cuerda vibra; la flecha de un hombre libre va a herir el corazón de un opresor.

-Al saberse esla noticia, se esparcen rápidamente el terror y la alegria. La acción de Tell inspiró el valor.,

¿No es, acaso, una hermosa historia? Y. sin embargo, no es Hisforia. sin que por eso deje de ser la más bella de las leyendas...

Distribuidas las objeciones, principia por constatarse la ausencia absoluta de todo testimonio contemporáneo. La crónica más antigua que habla de este héroe fué escrita a fines del siglo XV. por los años de 1482. Con anterioridad, dos cronistas del mismo siglo. que se refieren a los abusos de la dominación austriaca con notable minuciosidad, eno mencionan el nombre de Tell, ni hacen la menor alusión a sus hazañas o a su existencia. En la crónica de Zurich de 1479 no se halla referencia alguna a este respecto, *

La cronología y la geografia hablan, también, en contra de la historicidad de la tradición. SSi alguien quisiera estudiar esla pequeña Odisea, siguiendo un mapa, dice uno de los críticos, se encontraria tan embarazado como si se tratase de seguir las pistas a los héroes fantásticos de los viejos libros de caballerias. " .

Siguiendo el método analógico (de cuya existencia el señor Correa Pastene debe saber poco). la critica histórica se fué en busca. asimismo, de las leyendas similares que corrian por el mundo.

- Barros Arana: Una ilusión menos. Ob. Comp. T. 9, p. 13.

* Barros Arana: Art. cit. Ob. Comp. T. 9, p. 15. 
llegando a la postre a conclusiones como esta: .El hecho capital de esa hisloria (la de Tell) es la simple reproducción, ligeramente modificada, de ciertos sucesos verdaderos o invenlados que refieren las más viejas crónicas del norle de Europa...

Todavia existe un argumento etimológico: Toll, en alemán, quiere decir lemerario: y tellum, en latin, significa dardo...

Eslá demás decir que los suizos defendieron durante largo tiempo con brio singular la historicidad de la leyenda. Cuando, en 1760. Uriel de Freudenberger publicó en Berna, en forma anónima, un libro titulado Guillaume Tell, fable danoise, provocó en el pais grande alboroto e irritación, hasta verse obligado el gobierno del cantón de Uri a quemar aquellas páginas por la mano del verdugo, pidiendo, al mismo tiempo, al Senado de Berna la cabeza del aulor. Freudenberger. Guardó lan escrupulosamente su secrelo, escribe Barros Arana, que en nuestro tiempo se han necesilado grandes trabajos de erudición para llegar a descubrirlo.

A pesar del aspecto supersticioso que presenta, debo confesar que resulla conmovedora esla inconscienle fidelidad de los hombres, por los buenos cuenlos que aromaron los primeros sueños de su infancia. Ya lo dijo el poeta:

And, after all, what is lie? Tis but the truth in masquerade; and I defy. historians, heroes, lawyers, priests, to put a fact without some leaven of a lie.

Paradójico o no, hay quienes batirian como una bandera este desafio del escéplico inglés.

- Barros Arana: Art. cit. Ob. Comp. T. 9. p. 15.

* Barros Arona: Art. cit. Ob. Comp. T. 9. p. 12.

-.. Byron: Don Juan.-Canto XI-Stanza 37. - Después de todo, ¿qué cosa es una mentira? - No es ofra cosa que la verdad enmascarada.-Y yo de salio a hisforiadores, héroes, abogados o sacerdofes, a presentar un hecho sin los realces de la menfira." 
Don Misael Correa Pastene, hablando de Las fiestas nupciales en Venecia, en un número anterior de esta revista, escribe lo siguiente: Ningún historiador podrá fijar la fecha en que principia esla fiesta llamada de Los novios o edelle Maric. porque... ninguna cosfumbre nace de un edicto o aclo público de que se tome nota en los archivos.

Estoy de acuerdo con el señor Correa en la última proposición-lo prueban mis arliculos anteriores sobre este mismo tema:-en lo que no esloy de acuerdo es en que el cuento de sas fieslas nupciales, sea histórico, como no lo es tampoco el de slas Nupcias del Dux con el Adriálicos.

El argumento en contra lo tiene el señor Correa en cl mismo libro del cual obluvo conocimiento de esla leyenda, que dice de ella, textualmente, que sfué fundada más bien sobre tradiciones legendarias que sobre un hecho histórico a prueba de critica y documentación.

$\mathrm{Y}$ lermino esta ya larga polémica, sintelizando mis observaciones en tres puntos:

1) Don Misael Correa Pastene no puede citar un solo testimonio de historiógralo contemporáneo de prestigio. que sostenga el origen que èl viene dándole a la ceremonia de las nupcias del Dux con el mar Adriático:

2) Que, tanto esta ceremonia, como las realizadas en slas fiestas nupciales», son de origen legendario;

3) Que ambas ceremonias tienen similitud con otras celebradas en paises y épocas diversos, lo que ha inducido a la critica histórica a efectuar el trabajo scomparativos de rigor.

Aqui deberia poner mi firma; pero debo una explicación a los que leyeron el arlículo del señor Correa a que me he venido refiriendo. Son efectivas-aunque sin ningún mérito desde el punto de vista de las pruebas, - las citas que hizo el señor

- Errázuriz Urmeneta: La Ciudad de los Dux, pág. 207 Roma, 1917. 
Correa al hablar de slas bodas del Dux con el mars. La edición que tengo de la Historia de Daru es la primitiva, en siete tomos, y que se publicó con el lítulo de Hisfoire de la Republique de Vénise, por Fermin Didot, simprimeur du Roi. et de l'Institut,, Rue Jacob N. ${ }^{\circ} 24$, Paris.

Los que quieran darse cuenta de la pobreza informativa de Daru sobre la leyenda en cues-

tión, pueden consultar en la edición citada el tomo I, página 216. 